\title{
Reflexivity and ethical research practice while interviewing on sexual topics
}

\section{Abstract}

Reflexivity is a multimodal research feature that relies on the researcher's subjectivity and self-awareness. This article discusses uses of reflexivity when carrying out qualitative in-depth interviews on sexual topics. Through extracts of a challenging interview, where the challenge comes in the form of sexualised provocation from one man to another, this article considers the benefits of using reflexivity to address emerging complexities in the interview process. The discussion focuses on ethical research practice through the lens of three forms of reflexivity: (1) reviewing the values that underpin a research project, with emphasis on the tension between rationality and intuition; (2) emotional self-awareness and self-care; and (3) recognition of the power dynamics in the researcher-participant relationship. Reflexivity promotes an intuitioninformed decision-making process as a means to achieve ethical practice and conduct interviews with sensitivity and proficiency.

Keywords: in-depth interview, interviews on sexual topics, reflexivity, emotional awareness, researcher's safety, intuition.

In-depth interviews are intersubjective encounters in which researcher and participant engage in an act of telling, listening, and meaning-making in order to understand aspects of a specific topic. Given that it is the researcher who facilitates the meeting, introduces the topic, and is ultimately interested in understanding aspects of that topic in which the participant is experienced, the interview is an asymmetric and power-imbalanced encounter between two unequal partners (Lowes \& Paul, 2006). Participants, however, may put themselves in a powerful position as well, for example through their decisions about how much to reveal to the researcher 
1 and they impart information (Grenz, 2005). Power relations in the interview are thus dynamic

2 processes that involve cognitive and emotional engagement in the stories being told. The 3 researcher needs to remain aware of how power manifests itself before, during, and after the

4 interview to carry out the data collection appropriately and ethically.

Although there are personal, institutional, and social conceptions that make research on

6 sexuality a complex task (Irvine, 2014), some participants might be pleased to talk about these

7 aspects of their lives as the interview creates an atmosphere of intimacy that facilitates an easiness

8 in which sensitive stories about love and sex can be told. The level of attentive listening, emotional

9 sensitivity, and the researcher's aim to understand the interviewee's experiences contribute to a

10 level of 'connectedness' between them that can resemble a psychotherapeutic session

11 (Etherington, 2007; Hart \& Crawford-wright, 1999). This connectedness can help the participant

12 to feel at ease and make the interview more fruitful. However, the emotions attached to sexuality

13 can inundate the already intimate conversation to the point that the very act of talking might be

14 'arousing' and affect both researcher and participant (Grenz, 2005). Interviews on sexual topics

15 might also resemble the type of encounter that occurs when two strangers meet for an arranged

16 sexual relationship (Walby, 2010). This resemblance might pose challenges neither the researcher

17 nor the participant are prepared to tackle, for example, the unintentional and subconscious

18 sexualisation of the interview (Sanders, 2006).

19 In this paper, I address the difficulties that researchers and participants may experience

20 when stories of sexual and emotional intimacy are discussed in the context of in-depth interviews.

21 These difficulties can take many forms. Here I use an example of a participant who felt at ease

22 while talking about sexual practices but was reluctant about disclosing his struggles with emotional

23 intimacy. His decision-making process to solve that reluctance took a particular form of trust 
1 building. The man was vulnerable - but loath to admit it - yet found himself volunteering to take

2 part in my research interview. It was clear that he felt the need to test me: to make sure that I was

3 safe before he could trust me.

$4 \quad$ Understood as 'the process of critically reflecting on one's approach to research' (Lincoln

5 \& Guba, 2000, cited in Morrison, 2015, p. 53), reflexivity in research can take different forms.

6 Finlay (2008) calls one of these forms, 'reflexivity as intersubjective reflection', which involves

7 turning 'a critical gaze towards the emotional investment [researchers] have in the research

8 relationships concerned' (p. 8). When strong emotional reactions emerge during the research

9 process, these can be used to understand the researched phenomenon. In this light, I locate my

10 research practice in an onto-epistemological framework that conceptualises interviews as

11 'conversations' in which both the researcher and participant affect each other in ways they are not

12 always aware (Anderson, 2012). I also view the interview process as the co-construction of a

13 reality that is exclusive of the circumstances in which the interview takes place. In other words,

14 what happens during the interview is therefore unique to the time and space in which that particular

15 researcher and participant meet. (Flyvbjerg, 2001; Gergen, 2015; Rizq, 2008). From this

16 perspective, I argue both parties are responsible for what occurs during the interview. Ethically, I

17 adhere to minimising the power imbalance between interviewer and interviewee. I aim to avoid a

18 position where the researcher controls most aspects of the encounter and participants respond

19 merely as passive subjects. However, I acknowledge that there is an inherent power disparity in

20 the dyad, given that even when the interview is concluded, researchers retain certain privilege to

21 write about their understanding of the encounter using their scholarly knowledge. As Adams

22 (2008) writes, 'In terms of narrative ethics, I realize that every time I write my story, I escape

23 textual debate with the people I textually implicate.' (p. 180). Throughout the article, I will explain 
1 the tactics I use for minimising this power imbalance. In doing so, I show how researchers

2 inevitably represent incomplete and partial views of the participants and the experience of the 3 interview itself.

$4 \quad$ The reflexive analysis I present here might be of help to researchers who are in the process

5 of interviewing participants on sensitive topics and have struggled with challenging situations that

6 involved sexualisation of the interview. I consider three aspects of reflexivity: (1) the use of

7 reflexivity as a means of identifying the values that underpin a research project, thus allowing

8 researchers to ensure they act in accordance with those values; (2) the use of emotional awareness

9 as a reflexive skill to protect the participant and the researcher; and (3) acknowledgement of the

10 power dynamics in the researcher-participant relationship as a way to foster communication during

11 the interview and ethical research practice after conclusion of the interview.

\section{Research background}

13 For my doctoral research project, I explored how self-identified gay men give meanings to

14 their romantic and erotic relationships and how these meanings entangle with their sense of

15 identity. I made arrangements to interview 10 men of different ages and backgrounds, based

16 throughout the UK. In advance of the interview, I provided them with an electronic copy of an

17 information sheet and a consent form. The information sheet included key themes that we could

18 cover, for example: people with whom participants have been in love; circumstances in which they

19 feel sexual desire; relationships in which they have been involved; or the meanings that being

20 single or partnered has for them. The venue was selected at the participant's preference, choosing

21 from a university venue, their workplace, their home, a community centre, or any other place that

22 offered the possibility of holding a private conversation. 
Since my research required the interviews to be open, fluid, and 'organic discussions'

2 (Etherington, 2007) based on what mattered to them, I used an unstructured interview approach

3 that contributed to developing the interviews in a flexible way; participants leading the

4 conversation in terms of the content, and me responding to its particular themes and dynamics. My

5 chosen approach was influenced by my background in counselling studies, where unstructured,

6 open-ended interview approaches are common practice (Jones, 2010). However, although the

7 unstructured interview approach could have influenced the somewhat 'dangerous' direction that

8 the conversation I am going to describe took, I used the method because it favoured my exploratory

9 inquiry on identity, in which I considered any attempt to organise a semi-structured interview, as

10 a constraint of the research findings. Put another way, as described by Rath (2008), the

11 unstructured interview approach encourages participants to talk about their experiences in relation

12 to - but also 'away' - from the central research question. I needed an approach that let participants

13 talk freely about their erotic and romantic relationships and their lives as gay men but also 'away'

14 from those topics. Throughout my fieldwork, I would listen to participants talking about some

15 topics seemingly unrelated to my research question, but during the data analysis, those apparent

16 diversions revealed a broader narrative that convinced me that this was an appropriate approach

17 for this research.

18 I started interviews with a review of the now signed consent form, which helped me to set

19 the framework for the interview. Some participants talked more easily; when they started the

20 conversation, I responded to that and the dialogue developed from there. In other occasions, it was

21 me who started by bringing a topic addressed in previous emails or phone calls. Building on their

22 comments as a start point was a rapport strategy that helped me to sense the interview situation

23 and its dynamics. These opening statements opened a space of what Hirst (2004) calls 'socialising' 
1 with the participants; an opportunity to build trust and prepare the conversation before they engage

2 in more intimate disclosures. All interviews were audio-recorded and later transcribed by me. The 3 quotations provided in this article are verbatim.

4 Some studies have reported that sharing some background information, especially the 5 sexual orientation of the interviewer/researcher/counsellor is important when working with 6 Lesbian, Gay, Bisexual and Transgender people (Haldeman, 2010; Malley \& Tasker, 2007; 7 Satterly, 2004). Accordingly, I chose to introduce myself as a researcher and as a gay man. I 8 assumed this would facilitate the dialogue because they would perceive me as being understanding 9 and empathetic about their stories as I could have an insider's perspective of common situations 10 faced by gay men. I assumed that my disclosure would help the participants perceive the research 11 relationship more balanced in terms of power distribution. My stance was in direct contrast to 12 interviews in which only participants reveal information about themselves.

13 The narration of participants' erotic and romantic relationships constituted the main body

14 of the interviews. It was therefore important that both the participant and I felt sufficiently at ease 15 to discuss what at times were very intimate topics of conversation. Ozturk (2011) writes, 'During 16 the interviews, special care was taken to motivate the participants to bring forward details and 17 themes in a longer, unconstrained and unfettered answer pattern.' (p. 1108). Similarly, having 18 sensed the dynamics between us, and having judged that the interview relationship was 'ready' 19 (i.e. I sensed ease in both the participant and myself); I invited them to talk about their relationships 20 and what they meant in their lives. The unstructured nature of the interviews made me rely on 21 general counselling skills such as active listening, clarification, gestural responses, empathetic 22 responses, self-disclosure, and summarisation (Neukrug, 2012), which fostered the dialogue with 23 the participants. 


\section{Ethical tensions before a challenging interview}

Not long after I started to advertise for participants, I received a call from a man with a

3 deep voice who was interested in participating in my research. I was thrilled by the immediateness

4 of his response to my research. We spoke over the phone once and exchanged various emails. The

5 following month we met at a coffee shop before heading to his workplace where the interview

6 took place. He requested that we meet at the coffee shop, which I saw as an opportunity to confirm

7 that his interest in the research was legitimate. I arrived 10 minutes early and saw a man, perhaps

8 in his 50s, wearing a three-piece grey tweed suit and a matching grey tie, sitting at a table. He

9 looked at me, waved, and invited me to join him. It surprised me that he recognised me

10 immediately. When I commented on that, he explained that he had googled me. I felt slightly

11 uneasy about that but assumed that he just wanted to confirm that this was a serious study, so I

12 carried on. After a thirty-minute conversation, the man in the tweed suit told me for the fourth time

13 that I needed to be very careful with his identity information. I had made it clear already via emails

14 that anonymity was guaranteed but as the man got closer to my face, lowered his voice, and double-

15 checked that nobody was looking, I understood that anonymity was of particular importance to

16 him. He then instructed me that from that moment on, I must avoid calling him by his real name.

His request for using a specific pseudonym was not unusual, but something was

19 domineering in the quality of his voice, gaze, and demeanour that made me feel nervous. He

20 commented on my ethnicity, the colour of my eyes, my beard, and how attractive he found those

21 features, all of which had left me feeling apprehensive. In that moment, I reminded myself of my

22 methodological considerations: 'Make the participant feel comfortable, don't make him feel he has

23 been inappropriate, avoid flirtatious rapport. Should I say thanks for the compliments and carry 
on with the interview? Shall I ignore the comments? Shall I tell him those comments make me feel

2 uncomfortable? Since I had thought about these scenarios in case flirtation happened, I had some

3 preparation for that as suggested by Grenz (2005); 'bring some light humour or make a

4 desexualised comment'.

5 Although I opted for the desexualisation of the comment, I questioned, as Haire (2010) did,

6 the feasibility of desexualising research that involves sex topics. I wondered, especially, to what

7 extent I could restrain myself from feeling sexual attraction. Karpathos was making flattering

8 comments about myself and the fact that he was my research participant did not change the fact

9 that I found him attractive. I felt guilty and unprofessional for feeling attracted to him. I considered

10 that remaining aware of my emotions and behaviour was all I could do, using introspection as 'a

11 springboard for interpretations' (Finlay, 2002), hoping that such reflection would help me get a

12 deeper understanding of my research relationship with that participant. I smiled and pretended not

13 to perceive his comments as flirtatious. My overriding concern was that I needed to protect my

14 research from losing integrity.

15 On a superficial level, he seemed to be testing how I would react to his seductive approach

16 but seeing it from a broader perspective; he could have unconsciously been relating to me as he

17 relates to gay men in general. However, in attempting to 'neutralise' his flirtation I find an

18 incongruence. I seemingly expected participants to disclose intimate romantic and erotic details,

19 while at the same time, feeling uneasy if they sexualised the situation. That initial flirtation was an

20 opportunity for me to understand how our respective experiences were affecting us both. Upon

21 reflection, I now observe that by desexualising the comment, I was inadvertently trying to recover

22 control of the situation after perceiving I was losing it to the hands of that participant and the

23 interview had not even started. 
Use of reflexivity to protect the participant

We moved on from the coffee shop to his workplace. I knew from earlier email

3 correspondence that he owned a shop. When we arrived there, we entered a showroom where there

4 were two women looking at a product for sale, one of whom appeared to work there, the other a

5 client. I mentioned something about a colourful artefact that was on display as we passed through

6 and into an office at the back of the shop. The conversation was fluid and he seemed enthusiastic.

7 Underneath, I was trying to work out how to transition smoothly from general conversation onto

8 the research question. Helpfully, his business talk then connected to discussion about a man with

9 whom he had a date. At that point, I asked his permission to turn on the audio recorder, he accepted,

10 and the interview officially started.

Researcher: So, we got here, to this theme of your job, because you were telling me

2
about... this man you were seeing. And I thought that theme would be, perhaps, one of

3
the aspects you'd like to talk about... Or not. It's up to you... You know, in general,

4

5
what I am trying to understand in my $\mathrm{PhD}$ is how gay men make sense of the interaction between their romantic and erotic relationships and their sense of identity. Particularly, in this interview, I want to talk about your romantic and erotic relationships and what these relationships mean in your life as a gay man. response of cold silence, I had doubts about what to do. I waited. He was taking deep breaths. I

20 wanted to ask if everything was okay but I felt I would be breaking a silence that was incubating

21 something important. I sensed he was reflecting, and I wanted to be respectful. I decided that if I

22 sensed that something was not right, I would intervene and offer guidance. The silence felt right,

23 though. Eventually, he started talking, jumping into the topic of sexual relationships. 
Karpathos: They mean nothing. They mean nothing... There's no difference... between those, erotic and romantic relationships, they all are looking for the same, they just want sex, sex, sex, sex; [more explicit mentions of sexual practices] sex is all they want.

Researcher: They? Who are you talking about?

Karpathos: Gay men... You just need to have a look at their profiles in any, any website; they don't put anything there about who they are, they just put pictures, very explicit ones; [references to genitalia] everywhere, nothing for the imagination. And that's the message, if you see a picture of someone's [specific body part] it's clear they're not interested in a relationship, they just want -sorry for my French, [reference to sexual practice]. They're one-night standers. And it's all what you're going to find... here and everywhere. That's not for me, I want only one man. But nobody wants that. They sleep with anything...

This frantic beginning was followed by a graphic description of a sexual encounter he had with one of the people he calls 'one-night standers'; an encounter he remembers with dissatisfaction. The explicitness of his talk would serve as a script for a hard-core porn movie. At that early stage of the interview, I was thinking 'How much explicitness do I need? My research benefits from these details, but does he benefit from this?' I was not scandalised; I was asking myself, 'Are you listening to this because it answers your research question or are you listening to this because you are personally curious? He seems happy to tell me all this now, but how will he feel later?'

Frankfort and Nachmias (1996) address the tension between '...the right of the researcher to research and acquire knowledge and the right of individual participants to self-determination, privacy and dignity'. Karpathos was keen to talk about his sexual practices, but I perceived there was extreme anger and deception in the way he was talking about gay men and himself. I perceived 
1 he was hurt, but I struggled to decide if I should explore those feelings or not. I was asking myself,

2 Is it only the participant's responsibility to discern what they want to reveal? What am I supposed

3 to do if the participant reveals too much? When exactly does it become too much?

$4 \quad$ Since I believe that in research there should also be a sense of benefit for the participant

5 (Kitchener, 1984), I was concerned about continuing the conversation about that particular sexual

6 encounter. I asked myself 'How does this help the participant?' Grafanaki (1996) says that having

7 access to people's intimacy is a privilege. I felt honoured by the trust he was having in me but

8 simultaneously, I felt his intense anger and explicit approach had an intention beyond just sharing

9 his story. His tone of voice also expressed despair about the experiences with the men he had

10 attempted to have some connection. I started thinking that he was partly using the interview as a

11 space to express those emotions, similarly to what Bourne and Robson (2015) describe participants

12 finding in the research interview a space resembling a therapeutic encounter. That made me

13 wonder to what extent the expression of that anger would be projected onto me for what I

14 represented. After all, I was a gay man and in his eyes, I may be associated with those gay men

15 towards whom he felt so angry.

\section{Protecting the researcher through emotional awareness}

17 When I prepared the application for the ethics committee to get approval for my research,

18 I dedicated hours to considering 'what could go wrong?', imagining the worst possible scenarios,

19 verging on the ridiculous. Some colleagues smiled in disbelief when I told them the safety

20 procedure I followed when I interviewed participants at their home because they did not think that

21 I could be particularly vulnerable. I did not think of myself, being a $1.80 \mathrm{~m}, 85 \mathrm{~kg}$, male researcher

22 as particularly vulnerable either. My notions of masculinity were threatened by the very idea of

23 being vulnerable during my interviews and, as Schwalbe and Wolkomir (2001) discuss, I was 
1 reacting by thinking of myself as autonomous and in control. Still, my supervisors and I

2 implemented a procedure of 'checking in' before and after the interviews when I visited

3 participants' homes. We did not have a 'checking in' system for interviews that were conducted at

4 workplaces because we considered them safer locations. Yet while I was interviewing Karpathos

5 in the office at his shop, I realised it was not only participants' homes which represented a

6 challenge; the very act of interviewing someone whose sense of control feels threatened by the

7 self-exposure that the interview represents was a challenge in itself. This became clearer when

8 Karpathos suddenly asked me about my sexual practices in what I tentatively interpreted as an

9 attempt to counter-balance the interview situation.

Karpathos: Have you ever had sex with someone on the first encounter?

11 I felt his question was invasive of my privacy but the situation was worsened because,

12 echoing Mügge (2013), I could not deal with the situation in the ways I would have done outside

13 the research setting. I thought: What did I do to trigger that question? What is the problem with

14 this question? Is there a problem at all? I'm having a close look at participants' intimate lives,

15 should I be upset if they ask me something similar in return? Should I just answer? One view could

16 be that while I was trying to build trust with a participant whose comments showed he had been

17 hurt in the past, I was, inadvertently, threatening his self-portrayal as a man who needed to be 'in

18 charge'. He, in return, was trying to make me expose myself in the way that perhaps, he felt

19 exposed.

Herlihy and Corey (2014) emphasise that, when facing ethical difficulties, it is fundamental

21 that the counsellor/researcher assesses their personal feelings before making a decision. However,

22 tolerating the uncertainty was a considerable burden as I was aware no ethics code would give me

23 the exact answer for my concerns. Karpathos's question about having sex on my first encounters 
1 affected me emotionally. For a moment, I considered answering because ambiguous responses to

2 participants' direct questions might discourage rapport and close off dialogue (Walby, 2010).

3 However, given the circumstances of that specific interview, I decided not to answer. I based my

4 decision on my responsibility of self-care and 'phronesis'; the practical judgement that helps the

5 researcher to respond wisely in specific circumstances (Bondi \& Fewell, 2016). Rather than

6 facilitating communication, answering that question would make the interview troublesome and I

7 felt I should not answer.

Researcher: I know we're talking about very private topics here and I appreciate it can be very hard to talk about these... themes. As we talked before, if at some point you feel you don't want to talk... About something specific, you're absolutely free to say so... In this case, it's me who has to say 'I don't feel comfortable answering this question'. Karpathos: So that's a yes.

Karpathos: You've had sex with men on the first time, yes. Women have been taught not to go to a man's place alone the first time. They're strangers, women have learnt

17
that, and I think it's a useful piece of advice for you too, because it's dangerous... Going to a stranger's house.

Researcher: I realised that. Why should that be dangerous? I trust you.

22 The real message behind my phrase 'I trust you' was: 'I trusted you to come here, please,

23 do not betray that trust'. However, the message was impregnated with fear. Part of me refused to 
1 believe that I could be in danger. I tried to conceal my fear. That was the beginning of a series of

2 acts of challenge and resistance; Karpathos would present himself as strong and intimidating, and

3 I would present myself as calm and unaffected. Although I understand my responses were aimed

4 at protecting myself, I see they did not do much to develop or deepen the dialogue. In the fear I

5 experienced with Karpathos, I failed to realise that it did not belong to me exclusively; it was a

6 shared feeling between us. In other words, I overlooked that feelings are better understood

7 relationally, as they do not belong solely to an individual but instead emerge from relationships

8 (Bondi, 2014). The multiple disappointments Karpathos experienced when trying to find a partner

9 were being relived in our encounter. Symbolically, the interview seemingly resembled one of those

10 past encounters that have left him hurt; we had spoken online to arrange an appointment, it was

11 clear it was a one-off interview, and we were to address intimate aspects. It looked close to the

12 one-night-stands he has had, and that made him look for proof that I was reliable, that I was not

13 like one of the men with whom he has slept. Put another way, by asking if I sleep with men on the

14 first day we meet, what he was possibly trying to find out was if he would be emotionally safe

15 with me, and if he would avoid feeling the same disappointment that he has experienced with other

16 men.

17 Acknowledgement of the power dynamics in the interview

18 From the silence I heard in Karpathos's office, I realised the woman I saw in the shop when

19 we arrived had probably left. When I heard him saying the words 'we're alone now', I experienced

20 a vacuum sensation in my chest. In case of extreme danger, I need to get to the showroom, break

21 the glass, jump through the window, and run towards a busy road - I thought - while I wondered

22 whether the window would be alarmed. The atmosphere of the interview, vaporous and volatile,

23 is not possible to be transcribed and my words are unable to deliver the ominous experience of 
1 being with him in that room, listening to the tone he was using and sensing the way he was looking 2 at me. For sex with a stranger? sex, and you're not exactly a stranger...

8 there was someone who knew I would be meeting him. That comment did not seem to change his 9 tone. I did not know why I was feeling scared. I just felt it.

$10 \quad$ Karpathos: You sound scared.

11 Researcher: I'm not.

12 Karpathos: I don’t buy it. You still sound scared.

13 Researcher: Do I?

14 Karpathos: Yes, you sound scared.

$15 \quad$ Researcher: Is that your intention?

16 Karpathos: ... Your body doesn't tell, but your eyes do. But you don't have to be scared

17 of me. There's no reason... for that.

18 Researcher: I know.

19 Karpathos: It seems you're an experienced guy.

20 Researcher: At doing interviews? Well, I like to think of me that way. 
That was a crucial point in the interview. I perceived the inflexion of his voice and his static

2 eyes piercing me as trying to provoke me sexually. I found myself sexualised by him, and although

3 unwanted during a research interview, his comment was making me feel, paradoxically, less

4 anxious. When he mentioned I should not be alone in a stranger's house, all I was imagining was

5 that scene on American Psycho; a naked woman running away from the handsome and dangerous

6 Christian Bale who is chasing her with a chainsaw. However, when he mentioned I was 'an

7 experienced guy', his phrase was accompanied by non-verbal communication that delivered a

8 sexual message. The perceived danger in the encounter was lost when I sensed he was immersing

9 in sexual innuendo, as it was familiar terrain. 'I can handle that' - I told myself. My reassurance

10 of being able to deal with the situation did not have much to do with my courses on qualitative

11 research or counselling training; it had to do with my familiarity with the eroticised social practices

12 of some gay men; in which gazes, comments, and behaviours aim to provoke sexual connections.

$13 \quad$ Researcher: Are you an experienced guy?

14 Karpathos: At scaring boys and then seducing them? Yes, boys like to think of me that

15 way.

$16 \quad$ Researcher: How do you scare them?

17 Karpathos: Well, you saw it already...

$18 \quad$ Researcher: Do you still think I was scared?

19 Karpathos: I'm pretty sure you were.

20 Researcher: I'm sorry to disappoint you.

$21 \quad$ Karpathos: So you're... fearless.

22 Researcher: Oh, I wouldn't say that, there are plenty of things that scare me. 
Karpathos: Examples...

Researcher: [Silence] Losing my legs... [Silence] Not being able to walk, to dance, to move... The open sea at night... loneliness... losing my mum...

In the exchange mentioned above, by asking 'Are you an experienced guy?' I challenged Karpathos. Showing myself - again - as if unaffected by the fear but making sure he perceived a subtle tone with sexual connotations in my response. Similarly, when I denied I was scared, I was reacting to Karpathos's domineering persona as a defensive and anxious response aiming to regain control of the interview. In so doing, I was ensuring my self-representation, as a researcher and as a man, remained intact. Put another way, by showing ourselves unaffected by the other, our mutual responses were creating a fight for power in which we were both trying to win.

When he called me 'fearless', I questioned why I felt I needed to present myself to Karpathos with the stoicism I was portraying. Bondi (2014), McVey, Lees, and Nolan (2015) argue that two people in conversation affect each other, whether they acknowledge it or not. They suggest that the content developed in the context of the interview does not belong exclusively to one of them; it belongs to both because it develops as an intersubjective exchange. Have we been sharing the same fear? - I asked myself. Seemingly, my anxieties were about the danger of being with a stranger who was also a potential threat. Could his fears be about disclosing difficulty and intimate feelings to a stranger? Could he be afraid that I was like the gay men about whom he has been disappointed? Whatever the answer, both Karpathos and I seemed to be resisting acknowledging ourselves as vulnerable men. I also realised that when I took the challenge of his sexual innuendo and responded in the same way, delivering a sexually charged non-verbal message, I was following

22 the pattern he had shown me. A pattern marked by the over-investment of energy in detailed sexual 
1 descriptions of his encounters and the avoidance to explore his co-responsibility in them.

2 Encounters he seemingly despises, but in which he still participates.

Paradoxically, the strategy that worked and brought us to a place of intimate and safe

4 dialogue was to show my vulnerabilities; an act of surrendering to his power, communicating that

5 the fight had finished. Disclosing some of my biggest fears was a twofold decision. First, I have

6 learnt that self-disclosure helps the dialogue to flow when one of the people in the conversation

7 struggles to share something (Neukrug, 2012). Second, my self-disclosure was further informed

8 by something more fundamental; the recognition and acceptance of my vulnerability, of how

9 power in the research relationships can be played by a researcher, participants, and even outsiders

10 (Thapar-Björkert \& Henry, 2004). In other words, Karpathos and I were entangled in the

11 unconscious dynamics of feeling invulnerable, competent, and self-efficient that did not allow us

12 to deal with our emotions constructively.

13 I do not know whether Karpathos could be dangerous, whether his behaviour during the

14 interview is representative of how he usually acts or that was just an unfortunate happening. Yes,

15 there were warning signs I underestimated for a number of reasons; my eagerness to complete my

16 fieldwork and my self-conception as non-vulnerable to sexual harassment are two examples.

17 However, when I overtly expressed my vulnerability, I accessed 'the emotion-saturated relational

18 space shared by researcher and participant' (McVey et al., 2015) and that act opened an insightful

19 space that was not accessible before. As the interview continued, Karpathos apologised for the

20 intimidating tone he used and talked about his emotional struggles. Whereas he previously avoided

21 talking about his feelings, he now disclosed sensitive information that made his voice break and

22 showed the fragility behind the controlling persona he had constructed around himself. 
Karpathos: [a relationship] hasn't worked... because they get scared of my opinions; religion is important for me and gay men tend to see it from a prejudiced point of view. All the negative, biased opinions they have about a person who is a follower of a religion, they attach... all those opinions to me. They see me as a bigot... That's why it hasn't worked for me... [Silence] Although it worked for me once... It worked, temporarily... [Tears] And it was pure and honest... I can't believe it, what's this! Look at me... Such a disgrace.

Researcher: Why do you say that?

Karpathos: Just look at me... crying. That's pathetic.

Researcher: I've cried several times, out of sadness... of joy, I cry a lot... I wouldn't like to think I'm pathetic because I cry.

Karpathos: Have you cried for a guy?

Researcher: For a few... Some of they have seen me cry... sometimes I've cried alone... [Silence] Are these tears for a guy?

Karpathos: It's a Greek story...

The Greek story happened to be the only relationship he has had in his life. That relationship made him transition from seeing himself as a straight man who only had occasional sexual encounters with other men, to self-identifying as gay. As it showed the relational aspect of identity and the impact that a meaningful partner can make on the construction of a gay identity, his disclosure of his Greek relationship provided one of the key findings of my doctoral research. A combination of factors played a part in the interview dynamics to get that level of trust. Firstly, the unstructured quality of my method gave the flexibility of speaking about what he was bringing to the conversation. As Gadd (2004) describes, when researchers work within a specific 
1 methodological framework, there might be a risk that they miss valuable opportunities to explore

2 the contents and meanings that participants address during the interview. As an individual

3 struggling with aspects of identity, the flexible approach of the unstructured interview provided an

4 opportunity that invited Karpathos to talk in a way that, however convoluted, was seemingly

5 beneficial for him.

6 Revisiting the interview with the perspective of time gave me the distance that Mauthner

7 and Doucet (2003) write about as the multi-layered reflexivity they have acquired once they have

8 distanced intellectually and emotionally from their projects. I could have minimised my struggles

9 when dealing with this particular interview if I had identified at an earlier stage my defensive

10 reaction to feeling vulnerable and disempowered. My self-disclosure played a crucial role in how

11 the fight for power we both engaged in was solved. However, this was only possible thanks to the

12 realisation of the relationality of emotions (Bondi, 2014; McVey et al., 2015).

\section{Final remarks and lessons learned}

14 Researching on sexual issues can be a complex task because of the stigma and prejudice

15 associated with sex and the limited literature on the difficulties associated with it (Irvine, 2014;

16 Štulhofer, 2014). Moreover, I overlooked that for some men - Karpathos and me, for example - it

17 might be more difficult to handle the emotional aspects of intimacy than the sexual aspects. As

18 Schwalbe and Wolkomir (2001) suggest, the act of being interrogated casts a sense of losing

19 control and puts the masculine self at stake. This makes me think that Karpathos' expressions of

20 control over me might have been a coping mechanism, to calm him down and remove his

21 inhibitions about talking about his feelings. I also wonder about the extent to which I was

22 privileging his wellbeing and the research success over my self-care, but that is not a question I

23 propose to answer here. 
In the end, the experience was productive and enlightening but distressing nonetheless. I

2 am aware that this interview was on the verge of ending on a negative note. The question I posed

3 when preparing my research design 'what could go wrong?', reminds me that an important aspect

4 of research practice involves self-care, which I underestimated during this interview. The findings

5 showed me that all participants provided rich narratives of intimate content whether the interviews

6 were conducted in an office, a university room, or participants' home, which suggests that the

7 freedom to disclose intimate content was not negatively affected by the venue. With hindsight,

8 meeting first in a social setting might have influenced the way in which the interview later

9 developed. In future projects I would not readily agree to this kind of request because to do so

10 might be misinterpreted and read outside the context of a research setting.

11 The encounter between Karpathos and I was only the second interview I conducted for my

12 doctoral project. I feared that I had done something wrong and that this experience would taint the

13 rest of my interviews. Consequently, I wrote about this experience as a way to understand what

14 happened and prevent it from happening again. I wrote introspectively and then shared my writing

15 with my supervisors and colleagues in a research seminar on ethics. The writing helped me to

16 process the feelings related to the interview and transformed the introspection into 'mutual

17 collaboration' (Finlay, 2008), which allowed me to hear multiple voices, some of which were

18 challenging. One of the first challenges was the realisation that there was a tension between my

19 researcher role and my 'insider perspective'. What I mean by an insider perspective is my sense

20 of belonging to a gay community. Because I have interacted with various milieus advocated to gay

21 men, I hold knowledge that does not come from my training as a researcher but from being a gay

22 man. Throughout my life, I often experienced how some interactions between gay men became

23 sexualised. Similarly, literature in gay men's studies has shown that relationships between gay 
1 men tend to blur the boundaries between being friends and being sexual partners (Nardi, 1992;

2 Thomas II, 2008). This narrative resonated with me and with all the participants in my study. The

3 reasons for these sexualised interactions are varied and it is not the aim of this article to explain

4 them. However, what is relevant here is the reflection that my 'insider perspective' was a particular

5 aspect that I needed to consider throughout the conduction of my research. With most of my

6 participants there was a degree of sensuality during our conversation; the narrations of their

7 experiences were often erotically charged and I participated, through my active listening and my

8 mere presence, in the co-creation of those erotic narratives. For example, with one of the

9 participants there was a sense of erotic tension when he was sharing his experiences of cruising;

10 there was pleasure in his telling, in my listening, and in the exchange. With another participant,

11 there was the occasional flirtatious smile and wink that he would use as a way to relate to me while

12 he was sharing his stories of sexual adventures. Those interviews were erotic. It was a shared

13 pleasure; a pleasure that depended on the other and fed the other. However, what distinguished the

14 interview with Karpathos, and the reason for my focus on that particular interview in this article,

15 is that with Karpathos I failed to listen to my 'intuition' telling me that something in the interaction

16 was not right. Flyvbjerg (2001) writes: 'Intuition is the ability to draw directly on one's own

17 experience - bodily, emotional, intellectual - and to recognize similarities between these

18 experiences and new situations. Intuition is internalized; it is part of the individual.' (p. 21) Whilst

19 there were various points in which the encounter with Karpathos provoked adverse bodily

20 reactions such as raised heartbeats and a hint of fear from the moment we were at the café, I did

21 not act upon those bodily reactions because of a combination of factors. One of the most powerful

22 grounds for not cancelling the interview - even when the idea crossed my mind - was

23 rationalisation. I rationalised that I did not have 'evidence' to support that he was dangerous. I 
1 rationalised that men are less vulnerable to sexual abuse. I rationalised that the risks were possible

2 but not probable. From the meeting at the café with Karpathos, I rationalised that even though I

3 felt there was something strange about the way he looked at me and spoke to me, all I had to

4 support a decision to cancel the interview was my intuition. Because I had not considered my

5 intuition as part of the reflexive process, I carried on with the interview. However, it only became

6 clear to me that all my emotions were part of the reflexive process - and that my intuition was a

7 fundamental part of the reflexive process - when I realised that the erotic aspects that were

8 discussed during the interviews would potentially elicit a similar erotic response during the

9 interviews and that that was fine. What was not fine was that the sexualisation of the process was

10 done coercively. What was not fine was that my experience as gay man telling me: 'This does not

11 feel right. Cancel the interview' was overshadowed by my experience as a researcher telling me:

12 'You have a safety protocol in place, you were recommended to him by one of your colleagues,

13 you need to act professionally; carry on with your data collection'.

14 When writing about her strategies for dealing with the sexualisation of the dynamics when

15 conducting her doctoral research project, Mügge (2013) describes: 'I tried to remain professional

16 at all times, not to show any emotion of fear or anger' (p. 543). She reports how that defensive

17 approach did not work in minimising the sexualisation of the interviews. Like her, I tried to remain

18 'professional' whilst conducting the interviews, as if 'professional' meant 'unaffected by a

19 narrative charged with eroticism or by an attractive participant'. I was trying to select what I could

20 feel - e.g. empathy - and what I should not feel- e.g. attraction - during the interviews, devaluing

21 the importance of intuition. During the revision of this article, one of the reviewers pointed out

22 that I had written about trying to restrain myself from feeling sexual attraction, whereas the ethical

23 problem lay in the communication of that feeling in the research context, not the feeling itself. The 
1 reviewer's observation made me realise that whilst most of the interviews had a component of

2 eroticism present during the conversations, that eroticism seemed to be mutual and benign. In the

3 interview transcripts, I could detect a sense of mild playfulness between the participants and me.

4 There was a sense of participating in reciprocal conversations. In the transcript of Karpathos'

5 interview, however, there is evidence of an imbalanced exercise of power. Therefore, one of the

6 lessons learned is the key role that intuition plays in research practice. As described by Flyvbjerg

7 (2001), 'Compared to rational decision-making, intuitive decision-making has been neglected as

8 an object for scientific study, perhaps because science tends to emphasize analytical rationality as

9 its own tool.' (p. 17). Throughout my life, I have experienced interactions between gay men

10 becoming sexualised. In these encounters, I have been able to deal with complex situations.

11 However, because in my initial approach to these interviews I compartmentalised my roles as a

12 researcher and as a gay man, I did not fully integrate my intuition to my research practice. In the

13 last stages of the case I described here, my years of experience of being a gay man engaging in

14 different types of encounters with gay men informed my decision to deal with the critical situation

15 in a way that allowed me to de-risk the interaction. However, had I 'followed my intuition' earlier,

16 I would have cancelled the interview or arranged to conduct it elsewhere. When interviewing

17 Karpathos, my intuition was there, throughout our conversation but it was only until I gave way

18 and listened to it that I was able to succeed in conducting interviews based on my bodily,

19 intellectual, and emotional experience. This may relate to how it is easier to act on our feelings of

20 empathy for a participant who is struggling than it is to act on our attraction or to our fear.

\section{References}

22 Adams, T. E. (2008). A review of narrative ethics. Qualitative Inquiry(2), 175.

23 Anderson, H. (2012). Collaborative Relationships and Dialogic Conversations: Ideas for a Relationally

24 Responsive Practice (English). Family Process, 51(1), 8-24. 
Bilgehan Ozturk, M. (2011). Sexual orientation discrimination: Exploring the experiences of lesbian, gay and bisexual employees in Turkey. Human Relations, 64(8), 1099-1118. doi:10.1177/0018726710396249

Bondi, L. (2014). Understanding feelings: Engaging with unconscious communication and embodied $\begin{array}{llll}\text { knowledge. Emotion, Space } & \text { 40 }\end{array}$ doi:http://dx.doi.org/10.1016/i.emospa.2013.03.009

Bondi, L., \& Fewell, J. (Eds.). (2016). Practitioner research in counselling and psychotherapy : the power of examples: London, New York, NY : Macmillan Education/Palgrave.

Bourne, A. H., \& Robson, M. A. (2015). Participants' reflections on being interviewed about risk and sexual behaviour: implications for collection of qualitative data on sensitive topics. International Journal of Social Research Methodology, 18(1), 105-116. doi:10.1080/13645579.2013.860747

Etherington, K. (2007). Ethical Research in Reflexive Relationships. Qualitative Inquiry, 13(5), 599-616. doi:10.1177/1077800407301175

Finlay, L. (2002). Negotiating the swamp: the operation and challenge of reflexivity in research practice. Qualitative Research, 2(2), 209-230.

Finlay, L. (2008). The Reflexive Journey: Mapping Multiple Routes Reflexivity (pp. 3-20): Blackwell Science Ltd.

Flyvbjerg, B. (2001). Making social science matter : why social inquiry fails and how it can succeed again / Bent Flyvbjerg ; translated by Steven Sampson: Cambridge : Cambridge University Press, 2001.

Frankfort-Nachmias, C. (1996). Research methods in the social sciences (Fifth edition.. ed.). London: London : Edward Arnold.

Gadd, D. (2004). Making sense of interviewee-interviewer dynamics in narratives about violence in intimate relationships. International Journal of Social Research Methodology, 7(5), 383-401. doi:10.1080/1364557092000055077

Gergen, K. J. (2015). Relational being beyond self and community: New York : Oxford University Press.

Grafanaki, S. (1996). How research can change the researcher: The need for sensitivity, flexibility and ethical boundaries in conducting qualitative research in counselling/psychotherapy. British Journal of Guidance \& Counselling, 24(3), 329-338. doi:10.1080/03069889608253017

Grenz, S. (2005). Intersections of Sex and Power in Research on Prostitution: A Female Researcher Interviewing Male Heterosexual Clients. Signs, 30(4), 2091-2113. doi:10.1086/428418

Haire, B. (2010). No sex please in sexuality research. The American Journal Of Bioethics: AJOB, 10(7), 4344. doi:10.1080/15265161.2010.486848

Haldeman, D. C. (2010). Reflections of a gay male psychotherapist. Psychotherapy: Theory, Research, Practice, Training, 47(2), 177-185. doi:http://dx.doi.org/10.1037/a0019757

Hart, N., \& Crawford-wright, A. (1999). Research as therapy, therapy as research: Ethical dilemmas in newparadigm research. British Journal of Guidance \& Counselling, 27(2), 205-214. doi:10.1080/03069889908256265

Herlihy, B., \& Corey, G. (2014). ACA Ethical Standards Casebook (7th ed.). VA, USA.: American Counseling Association.

Hirst, J. (2004). Researching Young People's Sexuality and Learning about Sex: Experience, Need, and Sex and Relationship Education. Culture, Health \& Sexuality, 6(2), 115-129.

Irvine, J. (2014). Is sexuality research 'dirty work'? Institutionalized stigma in the production of sexual knowledge. Sexualities, 17(5/6), 632-656. doi:10.1177/1363460713516338

Jones, K. D. (2010). The Unstructured Clinical Interview. Journal of Counseling \& Development, 88(2), 220226. doi:10.1002/j.1556-6678.2010.tb00013.x

Kitchener, K. S. (1984). Intuition, critical evaluation and ethical principles: The foundation for ethical decisions in counseling psychology. Counseling Psychologist, 12, 43-55. 
Lowes, L., \& Paul, G. (2006). Participants' experiences of being interviewed about an emotive topic. Journal of Advanced Nursing, 55(5), 587-595. doi:10.1111/j.1365-2648.2006.03950.x

Malley, M., \& Tasker, F. (2007). "The Difference that Makes a Difference": What Matters to Lesbians and Gay Men in Psychotherapy. Journal of Gay \& Lesbian Psychotherapy, 11(1-2), 93-109. doi:10.1300/J236v11n01_07

Mauthner, N. S., \& Doucet, A. (2003). Reflexive Accounts and Accounts of Reflexivity in Qualitative Data Analysis. Sociology, 37(3), 413-431.

McVey, L., Lees, J., \& Nolan, G. (2015). Practitioner-based research and qualitative interviewing: Using therapeutic skills to enrich research in counselling and psychotherapy. Counselling and Psychotherapy Research, 15(2), 147-154. doi:10.1002/capr.12014

Morrison, E. (2015). How the I shapes the eye: the imperative of reflexivity in global service-learning qualitative research. Michigan Journal of Community Service Learning, 22, 52+.

Mügge, L. M. (2013). Sexually harassed by gatekeepers: reflections on fieldwork in Surinam and Turkey. International Journal of Social Research Methodology, 16(6), 541-546. doi:10.1080/13645579.2013.823279

Nardi, P. (1992). That's what friends are for, friends as family in the gay and lesbian community. In K. Plummer (Ed.), Modern homosexualities : fragments of lesbian and gay experience / edited by Ken Plummer (pp. 108-120): London : Routledge, 1992.

Neukrug, E. (2012). An introduction to the counseling profession : the world of the counselor. [Belmont, Calif.]: Brooks/Cole/Cengage Learning.

Rath, J. (2008). Training to be a volunteer Rape Crisis counsellor: a qualitative study of women's experiences. British Journal of Guidance \& Counselling, 36(1), 19-32. doi:10.1080/03069880701716208

Rizq, R. (2008). The research couple: a psychoanalytic perspective on dilemmas in the qualitative research interview. European Journal of Psychotherapy \& Counselling, 10(1), 39-53. doi:10.1080/13642530701869755

Sanders, T. (2006). Sexing Up the Subject: Methodological Nuances in Researching the Female Sex Industry. Sexualities, 9(4), 449-468. doi:10.1177/1363460706068044

Satterly, B. A. (2004). The Intention and Reflection Model: Gay Male Therapist Self-Disclosure and Identity Management. Journal of Gay \& Lesbian Social Services, 17(4), 69-86.

Schwalbe, M., \& Wolkomir, M. (2001). The Masculine Self As Problem and Resource in Interview Studies of Men. Men and Masculinities, 4(1), 90-103. doi:10.1177/1097184x01004001005

Štulhofer, A. (2014). Reflections from the periphery: A commentary on Irvine. Sexualities, 17(5-6), 681685. doi:10.1177/1363460714531275

Thapar-Björkert, S., \& Henry, M. (2004). Reassessing the research relationship: location, position and power in fieldwork accounts. International Journal of Social Research Methodology, 7(5), 363-381. doi:10.1080/1364557092000045294

Thomas II, M. E. (2008). A Towel and a TV. In A. R. Gottlieb (Ed.), On the meaning of friendship between gay men (pp. 67-72). New York: Routledge.

Walby, K. (2010). Interviews as encounters: issues of sexuality and reflexivity when men interview men about commercial same sex relations. Qualitative Research, 10(6), 639-657. doi:10.1177/1468794110380525 